\title{
Otimização da análise da atividade da redutase do nitrato e sua caracterização em folhas de cana-de-açúcar
}

\author{
Carlos Leandro Rodrigues dos Santos(1), Jairo Osvaldo Cazetta(2), Luciana Maria Saran ${ }^{(2)}$ e Adhemar Sanches ${ }^{(2)}$ \\ (1)Universidade Federal de Mato Grosso, Campus do Araguaia, Instituto de Ciências Exatas e da Terra, Avenida Valdon Varjão, no 6.390, \\ CEP 78600-000 Barra do Garças, MT, Brasil. E-mail: caleufrrj@bol.com.br (2)Universidade Estadual Paulista, Faculdade de Ciências Agrárias \\ e Veterinárias, Departamento de Tecnologia, Via de Acesso Prof. Paulo Donato Castellane, s/nº, CEP 14884-900 Jaboticabal, SP, Brasil. \\ E-mail: cazetta@fcav.unesp.br, Imsaran@gmail.com, adhesan@fcav.unesp.br
}

\begin{abstract}
Resumo - O objetivo deste trabalho foi padronizar e caracterizar as condições para determinação da atividade da redutase do nitrato em tecido foliar de cana-de-açúcar, com uso do método in vivo. Amostras foliares foram coletadas de uma lavoura de primeira soqueira da cultivar IACSP 933046, com idade de seis meses. Foram estudadas diferentes condições de preparo das amostras foliares e do meio de incubação. O material que possibilitou a maior atividade da redutase do nitrato foi obtido pela amostragem de 25 discos de $1 \mathrm{~cm}$ de diâmetro, coletados às $13 \mathrm{~h}$, do centro da folha do tipo +1 sem nervura. $\mathrm{O}$ meio de incubação otimizado para a determinação da atividade dessa enzima em folhas de cana-de-açúcar deve ser composto por: $2,5 \mathrm{~mL}$ de $\mathrm{KNO}_{3}$ $300 \mathrm{mmol} \mathrm{L}^{-1} ; 2,5 \mathrm{~mL}$ de tampão fosfato $285 \mathrm{mmol} \mathrm{L}^{-1} \mathrm{pH}$ 7,3; $1,0 \mathrm{~mL}$ de Tween 20 a $0,6 \%$ (v/v); e $4,0 \mathrm{~mL}$ de água deionizada. A maior atividade da redutase do nitrato é obtida pela incubação das amostras por 90 min, a $32^{\circ} \mathrm{C}$, no escuro; é observada em plantas jovens formadas pela brotação da soqueira; e alcança o valor mínimo na fase de maturação das plantas.
\end{abstract}

Termos para indexação: Saccharum, atividade enzimática, estádio fenológico, método in vivo, nitrogênio, ritmo diurno.

\section{Optimization of nitrate reductase activity analysis and its characterization in sugarcane leaves}

\begin{abstract}
The objective of this work was to standardize and characterize the conditions for determining the nitrate reductase activity in sugarcane leaf tissue, using in vivo method. Leaf samples were collected from a first ratoon crop of the IACSP 933046 cultivar, with six months of age. Different preparation conditions of leaf samples and incubation media were studied. The material that allowed the highest nitrate reductase activity was obtained by the sampling of 25 discs of $1 \mathrm{~cm}$ in diameter, collected at $13 \mathrm{~h}$ from the center of the +1 leaf type without center rib. The incubation medium optimized to determine nitrate reductase activity in sugarcane leaves must be comprised of: $2.5 \mathrm{~mL} \mathrm{KNO}_{3} 300 \mathrm{mmol} \mathrm{L}^{-1} ; 2.5 \mathrm{~mL}$ phosphate buffer $285 \mathrm{mmol} \mathrm{L}^{-1} \mathrm{pH} 7.3$; $1.0 \mathrm{~mL}$ Tween $200.6 \%(\mathrm{v} / \mathrm{v})$; and $4.0 \mathrm{~mL}$ deionized water. The highest nitrate reductase activity is obtained by incubating samples for $90 \mathrm{~min}$, at $32^{\circ} \mathrm{C}$, in the dark; is observed in young plants formed by stump sprouting; and reaches a minimum value at the plant maturity phase.
\end{abstract}

Index terms: Saccharum, enzymatic activity, phenological stage, in vivo method, nitrogen, diurnal rhythm.

\section{Introdução}

A cana-de-açúcar (Saccharum officinarum L.) é considerada a principal matéria prima para a produção de biocombustíveis renováveis no mundo (Miller, 2010); e, portanto, é grande o interesse por conhecimento relacionado à cultura. Muitos fenômenos ligados à aquisição de $\mathrm{N}$ pelas plantas de cana-de-açúcar ainda não estão bem esclarecidos, e práticas, como adubação, irrigação e correção do solo para o cultivo, precisam ser melhor estudadas.
A atividade da enzima redutase do nitrato $(\mathrm{RN})$ [EC 1.6.6.1] pode ser utilizada como ferramenta complementar para interpretações de resultados experimentais. Diversas linhas de pesquisa mostram a alteração dos níveis de atividade da enzima, ocasionada pela atividade da $\mathrm{RN}$, controlada por uma série de estímulos ambientais e intrínsecos à planta, que regulam os mecanismos transcricional, traducional e pós-traducional (Campbell, 1999; Konishi \& Yanagisawa, 2011; Mazid et al., 2012). 
O desencadeamento da expressão dos genes da RN é induzido pela presença de nitrato, enquanto o nível de expressão é controlado pela luz (Souza et al., 2002; Lillo, 2008), além de responder a outros sinais ligados ao próprio metabolismo do $\mathrm{N}$ (teor de glutamina), ao metabolismo do carbono (sacarose e $\mathrm{CO}_{2}$ ) e à fotossíntese (energia e citocininas) (Crawford et al., 2000; Miller \& Cramer, 2004).

A proteína de transdução de sinal 14-3-3 é responsável pelo controle pós-traducional da $\mathrm{RN}$ em plantas. Nas junções entre os grupos prostéticos da enzima (resíduo de serina), pode ocorrer a fosforilação, seguida da ligação da proteína 14-3-3, a qual controla rapidamente e de forma reversível a atividade da $\mathrm{RN}$ em reposta à luminosidade ou à escuridão. Assim, no escuro, a proteína se liga ao fosfato do resíduo de serina e inativa a enzima, e, se as plantas forem expostas à luz novamente, ocorre o desligamento da proteína 14-3-3 e a enzima torna-se ativa outra vez (Crawford et al., 2000; Souza et al., 2002; Lea et al., 2006).

O nível de atividade da $\mathrm{RN}$ em tecidos de plantas é bastante influenciado pelo seu substrato, o íon $\mathrm{NO}_{3}^{-}$; por isso, a concentração de nitrato é importante controlador da atividade. Essa atividade também é controlada pelas condições ambientais e intrínsecas da planta, como temperatura do ar, luminosidade, balanço hídrico da planta, propriedades químicas do meio de cultivo (teores de $\mathrm{Al}$, de $\mathrm{NH}_{4}^{+}$, de nutrientes e $\mathrm{pH}$ ) e idade fisiológica dos tecidos (Taiz \& Zeiger, 2004; Sharma \& Dubei, 2005; Freschi et al., 2009; Cruz et al., 2011; Mazid et al., 2012). Além disso, a inoculação de bactérias fixadoras de $\mathrm{N}$ também pode interferir na atividade da RN (El-Komy et al., 2003; Donato et al., 2004). Contudo, cabe destacar que há outros mecanismos de controle ainda não elucidados (Konishi \& Yanagisawa, 2011; Mazid et al., 2012).

A atividade da $\mathrm{RN}$ pode ser determinada pelo método in vitro ou in vivo. $\mathrm{O}$ método in vitro apresenta, como desvantagem, a necessidade de extração da enzima, o que o torna mais laborioso. Já o método in vivo pode ser usado mais facilmente sem a extração da enzima; no entanto, como desvantagem, apresenta a necessidade de se adaptar às condições de realização do ensaio, conforme a natureza do tecido vegetal (Jaworski, 1971). Cada espécie de planta tem suas particularidades anatômicas e fisiológicas, o que faz com que seja necessário o estabelecimento de condições apropriadas para cada espécie. Estudos de otimização do método in vivo para diversas culturas são comuns na literatura (Chanda, 2003; Cazetta \& Villela, 2004; Ahmad et al., 2010; Bobade \& Khyade, 2012).

Atualmente, o relato mais aprofundado sobre o ajuste do método para cana-de-açúcar, no Brasil, foi publicado por Oliveira \& Magalhães (1989), que estudaram plantas de três meses de idade, cultivadas em casa de vegetação. Considera-se que plantas oriundas de condições de campo e em estádio fenológico mais avançado têm a necessidade de condições analíticas diferenciadas. Nesse sentido, são necessárias mais pesquisas no direcionamento da elaboração de protocolo confiável para a estimativa da atividade da RN em cana-de-açúcar.

O objetivo deste trabalho foi padronizar e caracterizar as condições para determinação da atividade da redutase do nitrato em tecido foliar de cana-de-açúcar, com uso do método in vivo.

\section{Material e Métodos}

A otimização e a caracterização do método para a estimativa da atividade da RN em plantas de cana-de-açúcar foram realizados em março de 2011. Já o ensaio em diferentes estádios fenológicos foi conduzido em 2012. Os materiais vegetais foram coletados de uma lavoura de aproximadamente 1,5 ha localizada em Jaboticabal, SP $\left(21^{\circ} 14^{\prime} 46^{\prime \prime} \mathrm{S}, 4^{\circ} 18^{\prime} 17^{\prime \prime} \mathrm{W}\right.$, a $575 \mathrm{~m}$ de altitude). A lavoura foi implantada em 2009, com a cultivar de cana-de-açúcar IACSP 933046. As plantas estavam em seu segundo ciclo produtivo, com aproximadamente 180 dias de idade. A análise química do solo, na camada de 0-20 cm, indicou: $\mathrm{pH}$ em $\mathrm{CaCl}_{2}$ de 6,$0 ; 19,0 \mathrm{~g} \mathrm{dm}^{-3}$ de matéria orgânica; $10,0 \mathrm{mg} \mathrm{dm}^{-3}$ de P (resina); 2,1 $\mathrm{mmol}_{\mathrm{c}} \mathrm{dm}^{-3} \mathrm{de} \mathrm{K} ; 37,0 \mathrm{mmol}_{\mathrm{c}} \mathrm{dm}^{-3} \mathrm{de}$ $\mathrm{Ca} ; 22,0 \mathrm{mmol}_{\mathrm{c}} \mathrm{dm}^{-3} \mathrm{de} \mathrm{Mg} ; 18,0 \mathrm{mmol}_{\mathrm{c}} \mathrm{dm}^{-3} \mathrm{de} \mathrm{H}+\mathrm{Al}$; SB de $61,1 \mathrm{mmol}_{\mathrm{c}} \mathrm{dm}^{-3}$; CTC de 79,1 $\mathrm{mmol}_{\mathrm{c}} \mathrm{dm}^{-3}$; e V de $77 \%$.

Para a estimativa da atividade da RN, foi utilizado o método in vivo estabelecido originalmente por Jaworski (1971), para folhas de soja (Glycine max L. Merril), e modificado por Cazetta \& Villela (2004) para Brachiaria radicans Napper.

Num primeiro momento, os ensaios foram iniciados com tecido das folhas do tipo +1 , que apresentam a última lígula superior visível e usualmente são utilizadas para determinar o teor de nutrientes minerais (Raij \& Cantarella, 1997). Para isso, foram coletadas

Pesq. agropec. bras., Brasília, v.49, n.5, p.384-394, maio 2014 DOI: 10.1590/S0100-204X2014000500008 
folhas provenientes de cinco plantas amostradas ao acaso dentro do canavial. As folhas foram coletadas às $10 \mathrm{~h}$ e levadas imediatamente para o laboratório (10 $\pm 5 \mathrm{~min})$. Com o auxílio de furador de rolhas, foram retirados, do ponto médio entre nervura central e borda da folha, discos de $1 \mathrm{~cm}$ de diâmetro. Foram testadas quantidades de material de 10 a 30 discos foliares. Os furos foram realizados no terço médio da folha, no sentido do comprimento. $\mathrm{O}$ tecido vegetal foi colocado em frascos protegidos da luz, contendo $10 \mathrm{~mL}$ de meio de incubação mantido em banho-maria a $30^{\circ} \mathrm{C}$, por $60 \mathrm{~min}$. $\mathrm{O}$ meio de incubação inicialmente testado e contido nos frascos era constituído por solvente [n-butanol 1\% (v/v)], detergente [Triton X-100 a $0,1 \%(\mathrm{v} / \mathrm{v})]$, solução de nitrato $\left(\mathrm{KNO}_{3} 60 \mathrm{mmol} \mathrm{L}^{-1}\right) \mathrm{e}$ tampão fosfato $\left(\mathrm{KH}_{2} \mathrm{PO}_{4} 200 \mathrm{mmol} \mathrm{L}^{-1} \mathrm{pH} \mathrm{7,4}\right)$, que foram submetidos, três vezes, ao vácuo de $-80 \mathrm{kPa}$, por 1 min (Cazetta \& Villela, 2004).

Ao final do processo, retirou-se alíquota de $0,5 \mathrm{~mL}$ do meio, que foi transferida para uma cubeta de vidro de $5 \mathrm{~mL}$. A seguir, foram acrescentados $0,5 \mathrm{~mL}$ de solução de sulfanilamida $10 \mathrm{~g} \mathrm{~L}^{-1} \mathrm{em} \mathrm{HCl} 3 \mathrm{~mol} \mathrm{~L}^{-1} \mathrm{e}$ $0,5 \mathrm{~mL}$ de dicloridrato de $\mathrm{N}$-(1-naftil)-etilenodiamina $0,2 \mathrm{~g} \mathrm{~L}^{-1}$. A mistura foi homogeneizada, e, após $20 \mathrm{~min}$, o volume foi completado a $4 \mathrm{~mL}$ com água deionizada e a absorbância foi medida em espectrofotômetro, modelo Spectronic 20D (Spectronic Instruments, Inc., Rochester, NY, EUA), ajustado para $540 \mathrm{~nm}$. A atividade da $\mathrm{RN}$ foi estimada em $\mu \mathrm{mol}$ de nitrito liberado por $1 \mathrm{~g}$ de tecido fresco por hora de incubação $\left(\mu \mathrm{mol} \mathrm{g}{ }^{-1} \mathrm{~h}^{-1} \mathrm{NO}_{2}^{-}\right.$) e foi calculada com base em equação linear obtida a partir do preparo prévio de curva-padrão.
O procedimento para a otimização da análise da atividade da RN nos tecidos foliares consistiu de ensaios experimentais sequenciais ao primeiro, com modificação de apenas um fator a cada ensaio, tendose tomado sempre, para os próximos ensaios, o maior valor de atividade da enzima observado no resultado do ensaio anterior, conforme sequência descrita na Tabela 1.

As análises para a caracterização da atividade da RN nas folhas de cana-de-açúcar foram realizadas em condições padronizadas, com execução da etapa anterior do experimento. Os dados meteorológicos aos quais as plantas estavam submetidas no período em que foram amostradas estão descritos nas Figuras $1 \mathrm{~A}$ e B.

Para a coleta das amostras de tecidos foliares frescos, foi necessária a definição da melhor posição na planta e da melhor porção da folha a ser coletada. Assim, para determinar a posição da folha na planta, realizou-se ensaio cujas unidades experimentais foram provenientes de cinco plantas ao acaso dentro do canavial. Os tratamentos foram constituídos dos tipos de folha: $0,+1,+2,+3,+4,+5$ e +6 , de acordo com classificação do sistema de Küijper, em que a folha +1 apresenta a última lígula superior visível; a folha 0 é a imediatamente superior a essa; a folha do tipo +2 é a subjacente à +1 , e assim por diante, até a folha +6 , que está localizada na parte inferior da planta. $\mathrm{O}$ ensaio foi analisado em delineamento experimental inteiramente casualizado, com três repetições.

Para a coleta de tecido na folha, as parcelas foram obtidas de 25 plantas, tendo-se coletado apenas as

Tabela 1. Caracterização dos tratamentos aplicados aos diferentes ensaios para otimização do método para determinação da atividade da redutase do nitrato em tecidos foliares de cana-de-açúcar (Saccharum officinarum).

\begin{tabular}{|c|c|c|}
\hline Ensaio/Unidade & Tratamentos & Número de repetições \\
\hline Tecido foliar (g) & $0,2-0,3-0,4-0,5-0,6$ & 4 \\
\hline Tempo (min) & $15-30-45-60-75-90-105-120$ & 3 \\
\hline Solvente & Acetato de etila - acetona - n-butanol - n-propanol - etanol - água & 4 \\
\hline Solvente $(\%)(v / v)$ & $0-1-2-3-4-5-6$ & 3 \\
\hline Detergente & Triton 100 - Tween 80 - Tween 20 - água & 5 \\
\hline Detergente $(\%)(\mathrm{v} / \mathrm{v})$ & $0,1-0,2-0,3-0,4-0,5-0,6-1,0$ & 3 \\
\hline $\mathrm{KNO}_{3}\left(\mathrm{mmol} \mathrm{L}^{-1}\right)$ & $0-30-60-90-180-270-360-450-540-630$ & 3 \\
\hline $\mathrm{pH} / \mathrm{KH}_{2} \mathrm{PO}_{4}$ & $5,4-5,8-6,2-6,6-7,0-7,4-7,8-8,2$ & 3 \\
\hline $\mathrm{KH}_{2} \mathrm{PO}_{4}\left(\mathrm{mmol} \mathrm{L}^{-1}\right)$ & $0-50-100-150-200-250-300-350-400-450-500$ & 3 \\
\hline $\begin{array}{l}\text { Condição de vácuo } \\
(-80 \mathrm{kPa})\end{array}$ & $\begin{array}{l}\text { Sem vácuo - uma vez por } 1 \mathrm{~min} \text { - duas vezes por } 1 \mathrm{~min} \text { - três vezes por } 1 \mathrm{~min} \text { - quatro vezes } \\
\text { por } 1 \mathrm{~min} \text { - uma vez por } 2 \mathrm{~min} \text { - uma vez por } 3 \mathrm{~min}\end{array}$ & 3 \\
\hline Temperatura $\left({ }^{\circ} \mathrm{C}\right)$ & $20-25-30-35-40-45$ & 4 \\
\hline
\end{tabular}


folhas do tipo 0, que, conforme o ensaio anterior, apresentaram maior valor médio de RN. Os tratamentos foram constituídos de tecidos provenientes do ponto médio entre nervura e borda, de diferentes porções ao longo da mesma folha: base, meio e ponta. Utilizou-se o delineamento experimental inteiramente casualizado, com sete repetições.

Para caracterizar a atividade da RN em cana-de-açúcar, nos diferentes horários ao longo do dia, cada unidade experimental foi constituída por uma mistura de cinco folhas do tipo +1 , coletadas de plantas amostradas ao acaso na cultura, tendo-se repetido o teste em três dias consecutivos. Os tratamentos foram constituídos pelos horários de coleta, com intervalos de 1 hora entre cada coleta. Portanto, foram utilizados 13 tratamentos, com início às $6 \mathrm{~h}$ e término às $18 \mathrm{~h}$, analisados em delineamento experimental inteiramente casualizado, com três repetições, sendo cada repetição constituída por média de quatro avaliações da atividade da $\mathrm{RN}$ por dia.

O acompanhamento da evolução do crescimento e do desenvolvimento da soqueira de cana-de-açúcar, bem como a atividade da RN em função do tempo após o corte, foi realizado mensalmente, de janeiro a novembro de 2012. O estádio fenológico foi classificado como descrito em Jadoski et al. (2010). Foram determinadas em cada um dos estádios fenológicos avaliados: a altura de dez plantas tomadas ao acaso, da superfície do solo até a inserção da folha +1 ; e a atividade da $\mathrm{RN}$, com quatro repetições, nas folhas +1 coletadas de cinco plantas, às $13 \mathrm{~h}$.

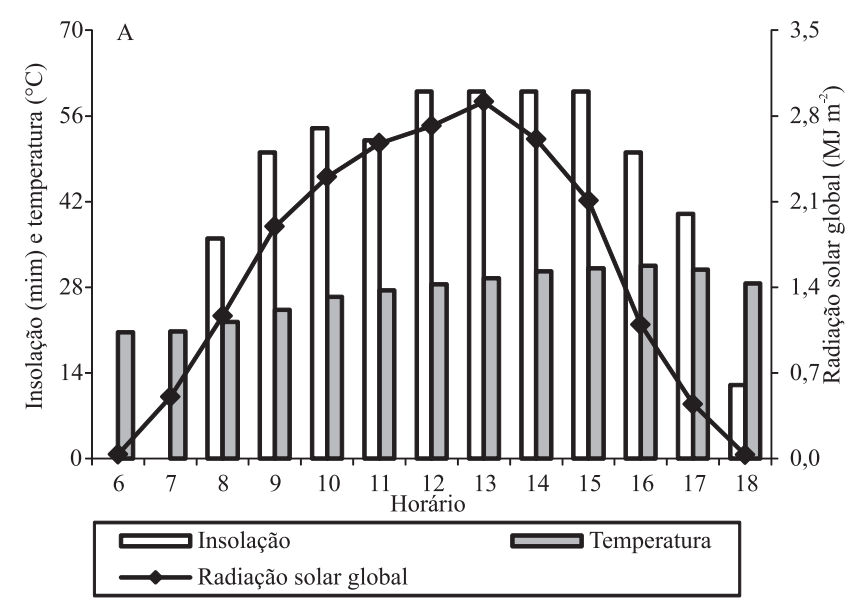

A análise dos dados foi realizada no programa estatístico SAS (SAS Institute, Cary, NC, EUA). Os dados obtidos em cada ensaio foram submetidos à análise de variância pelo teste F. Quando os resultados foram significativos, as médias qualitativas foram comparadas pelo teste de Tukey, a 5\% de probabilidade. No caso de variáveis quantitativas, os dados foram submetidos à análise de regressão polinomial. O cálculo do ponto de máxima nos casos de respostas quadráticas da atividade da $\mathrm{RN}$, para cada um dos ensaios, foi feito por derivação matemática.

\section{Resultados e Discussão}

Na otimização do método in vivo para estimativa da atividade da $\mathrm{RN}$, as leituras colorimétricas determinadas em espectrofotômetro aumentaram em função da quantidade de tecido foliar analisada. $\mathrm{O}$ contrário foi observado após a estimativa da atividade da enzima (Figura 2 A). Desse modo, ao se considerar a maior leitura colorimétrica e os limites de confiabilidade do espectrofotômetro, foi escolhida a quantidade de $500 \mathrm{mg}$ de tecido foliar, correspondente a 25 discos foliares com $1 \mathrm{~cm}$ de diâmetro cada um.

O prolongamento do tempo de incubação das amostras também causou o aumento dos valores de absorbância (Figura 2 B). Por sua vez, a atividade da RN decresceu até ponto mínimo aos $75 \mathrm{~min}$, mas foi somente a partir dos $90 \mathrm{~min}$ que as leituras colorimétricas se adequaram à faixa confiável do aparelho.

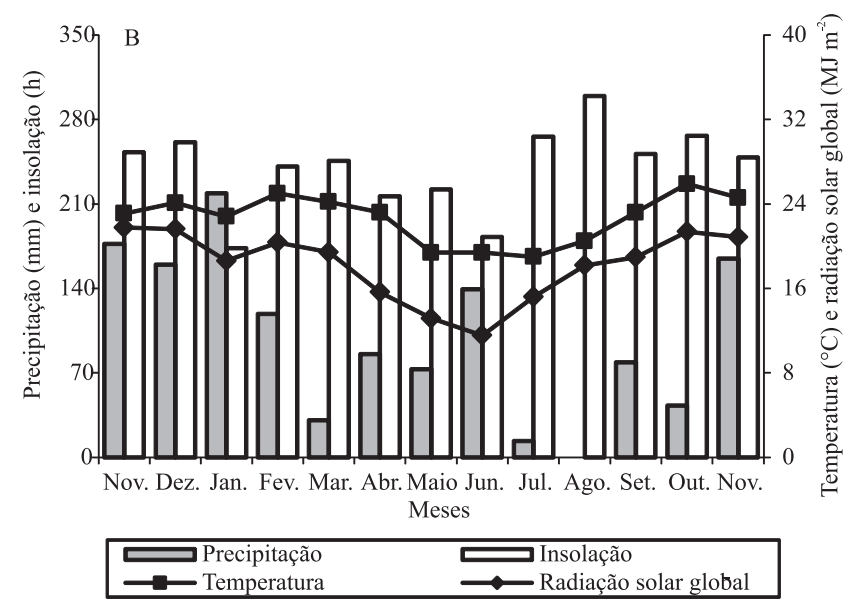

Figura 1. Dados meteorológicos obtidos na Estação Agroclimatológica do Departamento de Ciências Exatas da Universidade Estadual Paulista, Jaboticabal, SP. A, dados médios horários, em que cada dado corresponde à média dos dias 26,27 e 29 de março de 2011; B, precipitação mensal e médias mensais de temperatura, insolação e radiação solar global de 2012. 
Não foi constatada diferença significativa entre os solventes e os detergentes avaliados. Para confirmar esse resultado, montou-se um ensaio para avaliar diferentes concentrações de solvente e detergente, em que o solvente escolhido foi o n-propanol. Este solvente é o mais comumente utilizado nesse tipo de análise (Oliveira \& Magalhães, 1989). O detergente testado foi o Tween 20, em razão de sua mais rápida dissolução em água em relação aos demais avaliados. Concluiu-se que a aplicação do solvente interfere de forma negativa na análise, pois, à medida que se aumentou a concentração de n-propanol no meio de incubação, a atividade da $\mathrm{RN}$ diminuiu (Figura $2 \mathrm{C}$ ). Por essa razão, não se utilizou solvente nas avaliações experimentais seguintes. No método original para plantas de soja (Jaworski, 1971) e na maioria dos trabalhos de adaptação do método para outras espécies
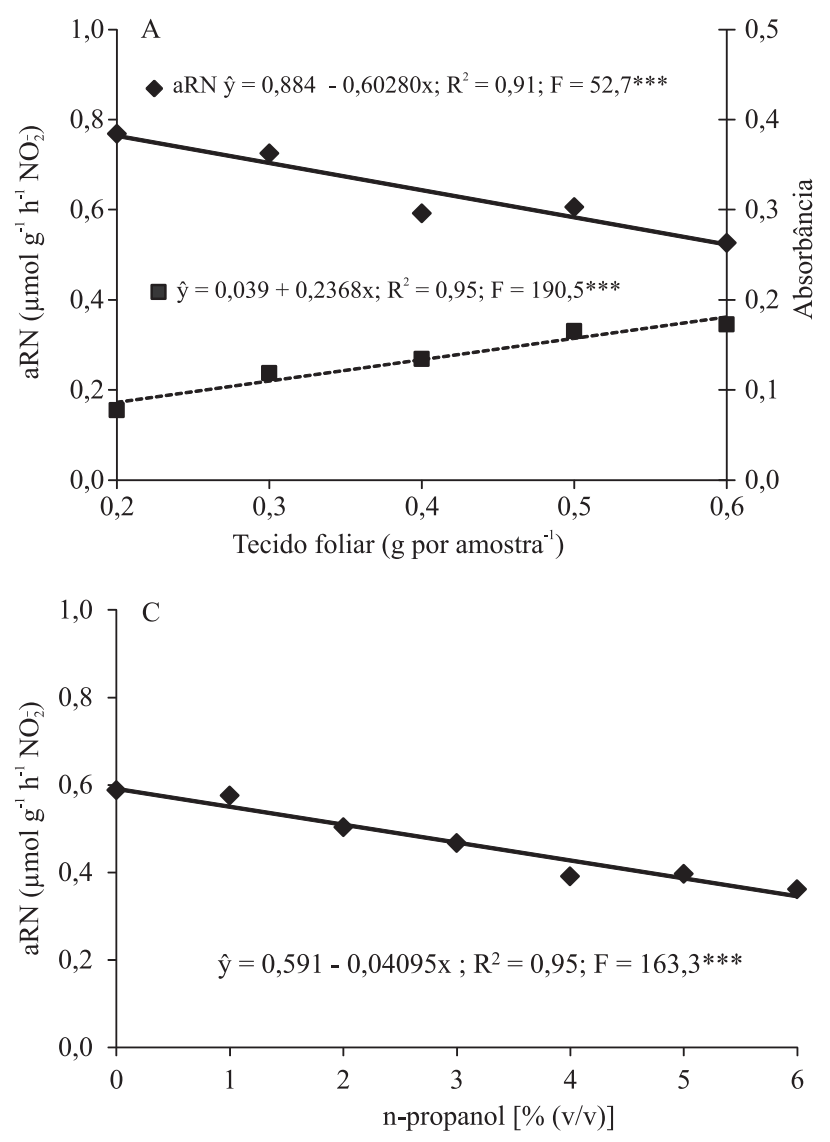

vegetais, com uso de diferentes concentrações e tipos de solventes (Chanda, 2003; Cazetta \& Villela, 2004), notou-se, em geral, a necessidade do uso de solventes no meio de incubação. Em contraste, outros autores não relataram o uso de solventes em suas análises (Ahmad et al., 2010; Bobade \& Khyade, 2012).

No método in vivo, é preciso que o nitrato do meio de incubação entre no interior das células e que o nitrito produzido seja difundido para o meio de incubação, para ser detectado. A função de solventes orgânicos e detergentes é promover a permeabilidade das membranas celulares (Jamur \& Oliver, 2010), além de diminuir a tensão superficial do líquido para facilitar o contato entre o meio de incubação e o tecido foliar (Cazetta \& Villela, 2004). Assim, esperava-se que, com a incubação dos tecidos de cana-de-açúcar em meio contendo algum tipo de solvente ou detergente,
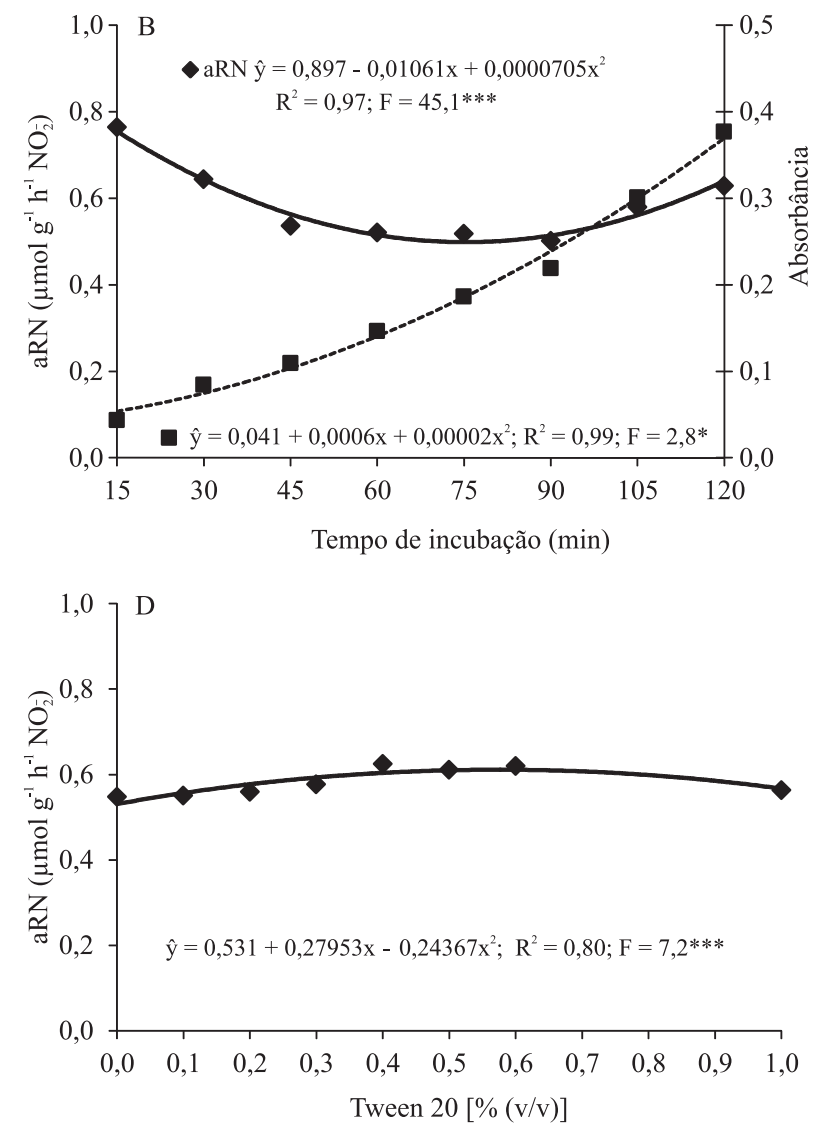

Figura 2. Atividade da redutase do nitrato (RN) em tecidos foliares de cana-de-açúcar (Saccharum officinarum), para otimização do método in vivo. A, estimativa da RN e leitura da absorbância em diferentes quantidades de tecido vegetal; B, RN e leitura da absorbância de amostras incubadas em diferentes períodos de tempo; $\mathrm{C}, \mathrm{RN}$ em tecidos foliares incubados com diferentes concentrações de n-propanol; D, RN em tecidos foliares incubados com diferentes concentrações de Tween

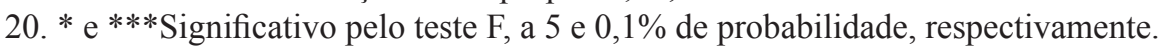


a atividade da $\mathrm{RN}$ fosse mais elevada que a do teste controle (sem esses aditivos); porém, isso não ocorreu. Ao contrário, houve menor atividade da enzima nos tecidos analisados com meio contendo solvente (Figura $2 \mathrm{C}$ ). Isso pode estar relacionado ao fato de alguns solventes orgânicos causarem a desorganização da configuração de proteínas (Jamur \& Oliver, 2010), grupo de substâncias em que se enquadra a redutase do nitrato.

Apesar de, aparentemente, não ser necessária a utilização de detergente no meio de incubação, optou-se pelo seu uso. Isso porque o detergente apresenta efeito permeabilizador de membrana, e, no geral, diminui a tensão superficial do meio de incubação e promove o imediato molhamento e a pronta submersão do tecido foliar no meio de incubação (Cazetta \& Villela, 2004), com aceleração do processo analítico. A concentração de Tween 20 que proporcionou a maior atividade da $\mathrm{RN}$ foi a de $0,6 \%(\mathrm{v} / \mathrm{v})$ (Figura $2 \mathrm{D})$.

$\mathrm{O}$ resultado do ensaio com diferentes concentrações de $\mathrm{KNO}_{3}$ confirmou a dependência do acréscimo de solução de nitrato no meio de incubação, pois, praticamente, não se observou atividade da $\mathrm{RN}$ no tratamento ausente de $\mathrm{KNO}_{3}$ (Figura $3 \mathrm{~A}$ ). Isso indica que, durante a análise, os tecidos foliares não acumularam nitrato suficiente para produzir nitrito detectável no meio de incubação.

Os dados de atividade da $\mathrm{RN}$ se ajustaram melhor à curva do tipo cinética, segundo a equação de Michaelis Menten (Nelson \& Cox, 2004), e tenderam ao
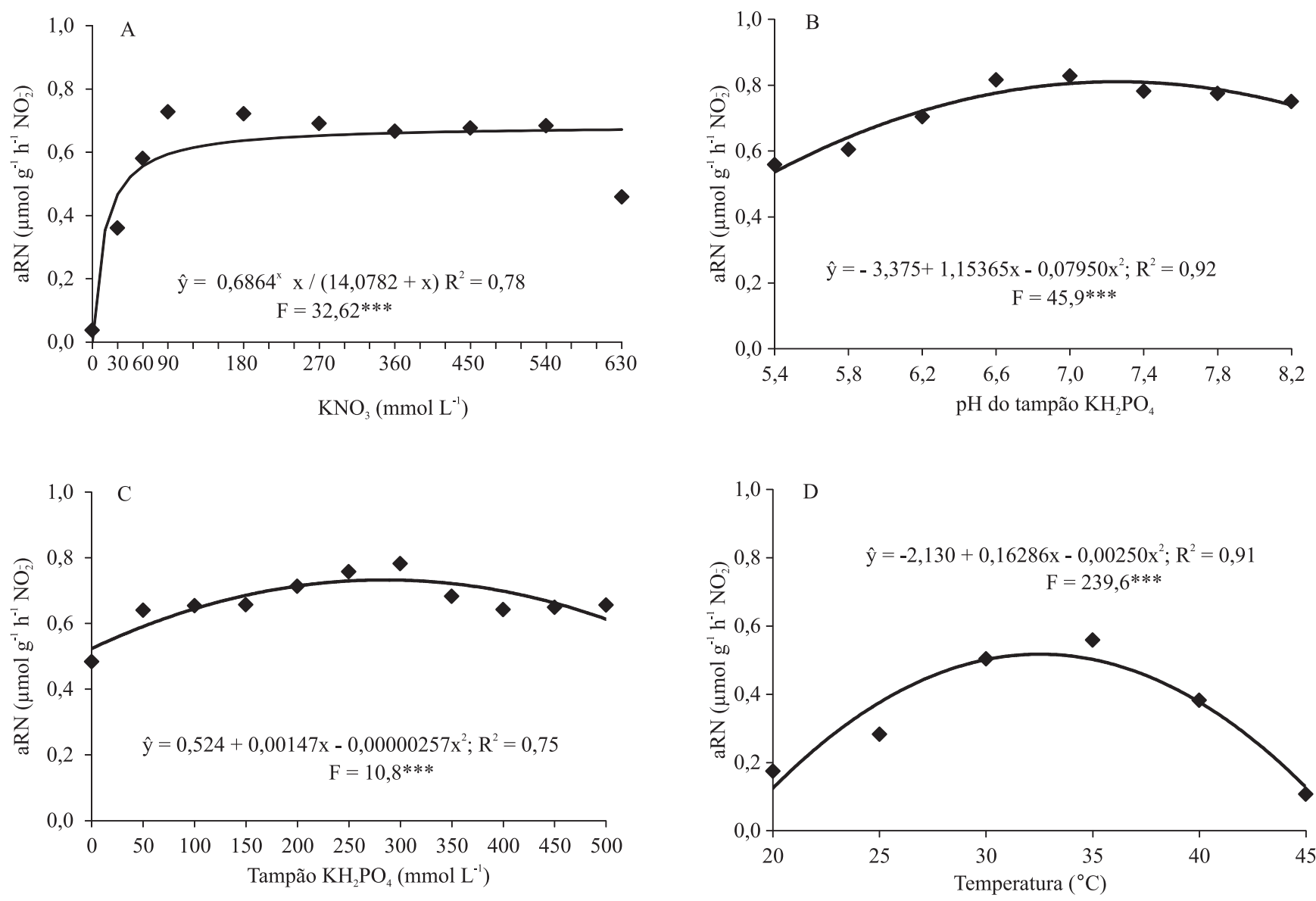

Figura 3. Atividade da redutase do nitrato $(\mathrm{RN})$ em tecidos foliares de cana-de-açúcar (Saccharum officinarum), para otimização do método in vivo. A, RN em tecidos foliares incubados sob diferentes concentrações de $\mathrm{KNO}_{3}$; $\mathrm{B}$, $\mathrm{RN}$ em tecidos foliares incubados com tampão $\mathrm{KH}_{2} \mathrm{PO}_{4}$, em função de diferentes valores de $\mathrm{pH} ; \mathrm{C}, \mathrm{RN}$ em tecidos foliares incubados com tampão $\mathrm{KH}_{2} \mathrm{PO}_{4}$, em função de diferentes concentrações; D, $\mathrm{RN}$ em tecidos foliares incubados sob diferentes valores de temperatura. ${ }^{* *}$ Significativo pelo teste $\mathrm{F}$, a $0,1 \%$ de probabilidade. 
aumento até a concentração de $180 \mathrm{mmol} \mathrm{L}^{-1}$; depois deste ponto, os valores permaneceram estáveis até $540 \mathrm{mmol} \mathrm{L}^{-1}$. O último ponto da curva $\left(630 \mathrm{mmol} \mathrm{L}^{-1}\right)$ não se enquadrou no modelo cinético; porém, esse ponto foi mantido no conjunto de dados para indicar que as leituras podem não ser mais seguras acima de $540 \mathrm{mmol} \mathrm{L}^{-1}$. Esta última concentração prejudicou a atividade da $\mathrm{RN}$, prejuízo que pode estar relacionado ao aumento da força iônica do meio que, penetrado no citosol, pode provocar alguma forma de desnaturação da proteína enzimática (Oliveira \& Magalhães, 1989).

A adição de nitrato no meio de incubação é essencial para a verificação da atividade potencial da RN. Contudo, concentrações baixas ou muito altas podem interferir na estimativa. Os resultados são indicativos de que não houve qualquer atividade da $\mathrm{RN}$ nos tecidos analisados sem $\mathrm{KNO}_{3}$. Esse resultado também foi relatado por Oliveira \& Magalhães (1989). Robinson et al. (2011) constataram que plantas de cana-de-açúcar absorvem preferencialmente amônio à nitrato em condições de similaridade nas concentrações de ambas as formas iônicas. O nitrato se acumula muito pouco em plantas de cana-de-açúcar, até mesmo quando aplicadas altas doses de N, o que sugere que é prontamente metabolizado ao chegar às folhas (Ishikawa et al., 2009).

Oliveira \& Magalhães (1989) verificaram que, na concentração de $300 \mathrm{mmol} \mathrm{L}^{-1}$ de nitrato no meio de incubação, não houve a diminuição da atividade da RN por aumento da concentração salina. Esses autores sugerem que uma alta força iônica poderia ser desenvolvida no citossol, onde está localizada a $\mathrm{RN}$, o que causaria desestabilização no complexo de subunidades que compõem a molécula da RN. Entretanto, no presente trabalho, até a concentração de $540 \mathrm{mmol} \mathrm{L}^{-1}$, os dados indicaram comportamento cinético natural da atividade da $\mathrm{RN}$ (Figura $3 \mathrm{~A}$ ). Somente na concentração de $630 \mathrm{mmol} \mathrm{L}^{-1}$ é que claramente foi observado prejuízo da atividade, o que indica que a concentração limite máxima deve estar em torno de $600 \mathrm{mmol} \mathrm{L}^{-1}$.

Assim, nesse método de determinação, devese garantir uma condição de saturação da enzima pelo substrato, para se desenvolver todo o tempo de incubação em situação de velocidade máxima da enzima. Em teores abaixo de $100 \mathrm{mmol} \mathrm{L}^{-1}$ de nitrato de potássio, a atividade enzimática é limitada pela falta de substrato (Figura $3 \mathrm{~A}$ ). Nessa situação, a resposta obtida seria uma função da concentração de nitrato no meio de incubação e não da atividade potencial da enzima. Por isso, deve-se trabalhar com uma concentração de nitrato que seja suficientemente elevada para que não venha a ser limitante, mas abaixo da concentração que poderia prejudicar a atividade enzimática. Dessa forma, a concentração de 300 mmol L-1 de nitrato no meio de incubação foi a escolhida como valor ótimo para a determinação da atividade da $\mathrm{RN}$ em cana-de-açúcar, uma vez que representa três vezes mais que a concentração mínima $\left(100 \mathrm{mmol} \mathrm{L}^{-1}\right)$ para a saturação da enzima obtida nas plantas avaliadas e corresponde a cerca de metade da concentração que prejudicaria a $\mathrm{RN}\left(600 \mathrm{mmol} \mathrm{L}^{-1}\right)$. Portanto, há uma margem de segurança tanto acima quanto abaixo dos $300 \mathrm{mmol} \mathrm{L}^{-1}$.

A atividade da $\mathrm{RN}$, em função do $\mathrm{pH}$ da solução tampão fosfato, atingiu ponto máximo com o valor de 7,3; porém, na prática, manteve-se estável na faixa de 6,6 a 7,8 (Figura 3 B). A concentração do tampão (pH 7,3) que proporcionou maior atividade da $\mathrm{RN}$ foi $285 \mathrm{mmol} \mathrm{L}^{-1}$ (Figura $3 \mathrm{C}$ ). Esta concentração foi maior que a de $50 \mathrm{mmol} \mathrm{L}^{-1}$ utilizada por Oliveira \& Magalhães (1989), que não avaliaram a otimização para essa variável.

A temperatura na qual as amostras foram incubadas influenciou a atividade da $\mathrm{RN}$, que atingiu ponto de máximo valor a $32^{\circ} \mathrm{C}$ (Figura $3 \mathrm{D}$ ). Os menores valores de atividade observados, com temperaturas acima e abaixo de $32^{\circ} \mathrm{C}$, podem ser atribuídos às alterações na permeabilidade das membranas. Isso pode diminuir a absorção e o transporte de nitrato para os sítios de redução no interior das células, bem como as alterações conformacionais da molécula da enzima, o que prejudica a sua função catalítica (Oliveira \& Magalhães, 1989).

Não houve diferença significativa na atividade da $\mathrm{RN}$ determinada nas diferentes condições de vácuo testadas, nem entre os testes com e sem aplicação da infiltração a vácuo. Com relação à caracterização da atividade da RN nas diferentes folhas da planta, foram obtidos maiores valores nas folhas mais jovens (dos tipos $0,+1,+2 \mathrm{e}+3$ ) do que nas mais velhas (dos tipos $+4,+5$ e +6 ) (Figura 4 A). Em contraste, Oliveira \& Magalhães (1989) constataram maiores atividades nas folhas mais velhas $(+3,+4 \mathrm{e}+5)$. Essa diferença pode ser atribuída às variações nas condições experimentais, uma vez que esses autores analisaram cana-planta com três meses de idade, cultivadas em vasos, e o presente trabalho foi desenvolvido a partir da rebrota das plantas 
(cana-soca), com seis meses de idade, cultivadas em condições de campo. Ao se levar em consideração que a atividade da $\mathrm{RN}$ nas folhas $0,+1,+2 \mathrm{e}+3$ não diferiu e que a folha +1 é a comumente indicada para análise do teor de nutrientes minerais, para avaliação do estado nutricional da planta (Raij \& Cantarella, 1997), também seria recomendável a indicação dessa mesma folha para a determinação da atividade da $\mathrm{RN}$.

No presente trabalho, as plantas foram analisadas aos 180 dias após o corte, idade em que a absorção de nutrientes, como o N, ainda é bastante alta (Silveira \& Crocomo, 1990; Jadoski et al., 2010). Na condição de campo, as raízes podem ter absorvido mais nitrato, o qual pode ter sido direcionado para os órgãos mais jovens com alta demanda por N. Com isso, mais substrato ficou disponível para a ação da enzima, e, como o nitrato é indutor da síntese (Campbell, 1999), a atividade da enzima foi mais intensa nas folhas jovens.

Em casa de vegetação, Oliveira \& Magalhães (1989) verificaram que o $\mathrm{N}$ provavelmente foi remobilizado

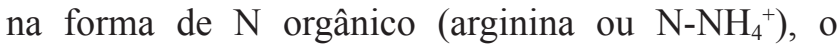
que pode ter ocasionado a menor atividade da $\mathrm{RN}$ observada nas folhas mais jovens. Contudo, as plantas de cana-de-açúcar estudadas por esses autores estavam com 90 dias de idade e não encontravam-se no período de máxima absorção de $\mathrm{N}$, que ocorre em torno de 150 dias após o plantio (Silveira \& Crocomo, 1990).

A posição de coleta de discos ao longo da folha também influenciou a atividade da $\mathrm{RN}$, tendo-se obtido menores valores na base das folhas, em comparação às demais partes (Figura $4 \mathrm{~B}$ ). Quanto à caracterização em diferentes horários do dia, constatou-se que as
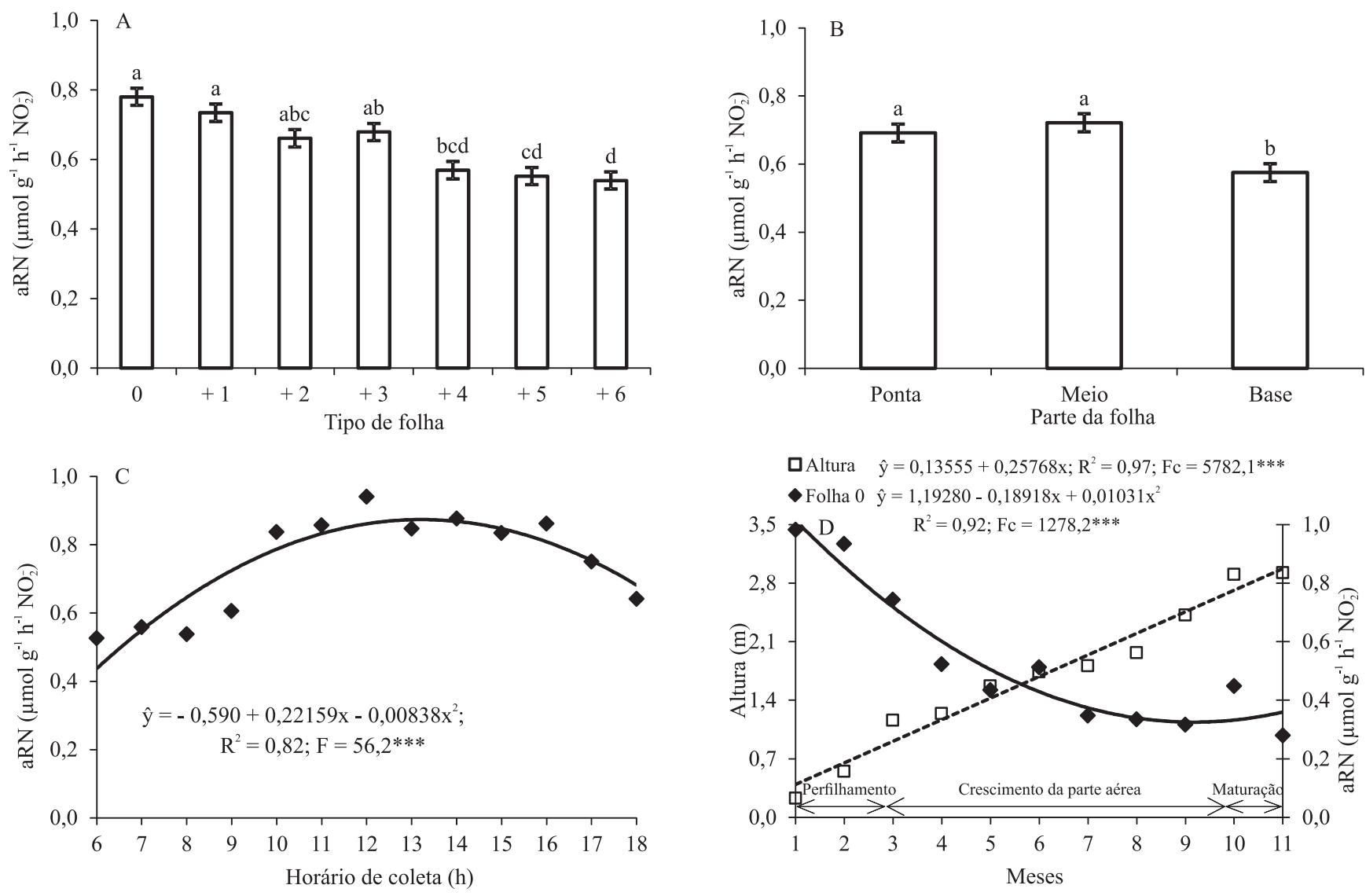

Figura 4. Caracterização da atividade da redutase do nitrato (RN) em tecidos foliares de cana-de-açúcar (Saccharum officinarum). A, RN em diferentes tipos de folha; $\mathrm{B}, \mathrm{RN}$ em diferentes partes da folha do tipo 0; $\mathrm{C}, \mathrm{RN}$ em diferentes horários ao longo do dia; D, RN e evolução da altura de plantas em função do tempo. Barras seguidas de letras iguais não diferem pelo teste de Tukey, a $5 \%$ de probabilidade. ${ }^{* * *}$ Significativo pelo teste $\mathrm{F}$, a $0,1 \%$ de probabilidade. A barra (I) nos histogramas representa o erro-padrão médio. $\leftrightarrow$, estádios fenológicos. 
maiores atividades da $\mathrm{RN}$ ocorreram nos períodos mais luminosos, com ponto máximo às $13 \mathrm{~h}$ (Figura 4 C). Dos fatores climáticos monitorados no período de realização do ensaio, a radiação solar global pode ter sido o que mais influenciou a atividade da RN. Os resultados sugerem que a enzima é mais ativa nos horários de maior intensidade de radiação solar global (Figuras 1 A e $4 \mathrm{C}$ ). A luz é capaz de influenciar tanto a transcrição de RNA mensageiro que codifica a $\mathrm{RN}$, como o controle pós-traducional da enzima (Lillo, 2008). Os baixos níveis de atividade da $\mathrm{RN}$ obtidos no início da manhã e no final do dia podem estar ligados a um mecanismo de controle rápido da atividade dessa enzima. Crawford et al. (2000) relataram que, na ausência de luz, ocorre a diminuição rápida dessa enzima, pois, nessa condição, a RN é fosforilada, e o grupo fosfato que fica ligado a um resíduo de serina, em uma das junções de dois grupos prostéticos da enzima, inativa a sua função catalítica. De acordo com esses mesmos autores, essa inativação da $\mathrm{RN}$ é reversível, pois, se ocorrer estímulo luminoso outra vez, o processo de fosforilação é revertido e a enzima volta a ficar ativa.

Às 13h, ocorreu o máximo de radiação solar global (2,92 $\left.\mathrm{MJ} \mathrm{m}^{-2}\right)$, que coincidiu com o ponto de máxima atividade da RN. Resultados semelhantes foram encontrados em folhas de plantas do tipo C3, que também apresentaram maiores reduções de nitrato em alta luminosidade (Lea et al., 2006; Kolton et al., 2012), diferentemente de folhas de plantas do tipo CAM, como o abacaxizeiro [Ananas comosus (L.) Merr.], em que essa enzima mostrou-se mais ativa no início da manhã (Freschi et al., 2009).

Quanto à variação da atividade da RN no decorrer do ciclo da cultura, verificou-se decréscimo, com 95\% de ajuste à curva do tipo quadrática (Figura $4 \mathrm{D}$ ). $\mathrm{O}$ ponto de mínima atividade da $\mathrm{RN}$ ocorreu na fase de maturação. As maiores atividades foram registradas logo no início da fase de perfilhamento, enquanto a altura das plantas aumentou de modo linear com o tempo, tendo atingido $2,97 \mathrm{~m}$ no último mês de análise (Figura 4 D).

O acompanhamento mensal da atividade da enzima iniciou-se no segundo mês após o corte da segunda soqueira da lavoura avaliada (janeiro de 2012). As plantas estavam com cerca de $20 \mathrm{~cm}$ de altura, na fase de perfilhamento, em pleno verão (Figura $1 \mathrm{~B}$ ). A alta atividade da $\mathrm{RN}$ observada nessa fase pode ser explicada pelas condições meteorológicas favoráveis à produção da enzima pela planta. Outro fator é que, em soqueira, o sistema radicular já está formado e é maior em relação à parte aérea das plantas, que era pequena até então. Portanto, independentemente da quantidade de nitrato disponível na solução do solo, essa teria sido suficiente para nutrir as plantas adequadamente. Além disso, Konishi \& Yanagisawa (2011) recentemente relataram a não dependência por nitrato para a síntese de RN. É possível que haja atuação de outros mecanismos que regulam a atividade da enzima após sua síntese.

A partir da avaliação realizada em abril, as plantas estavam no estádio de crescimento da parte aérea e iniciou-se o outono, com diminuição da luminosidade, da temperatura e da precipitação pluvial (Figura 1 B). Desse modo, além da mudança da idade das plantas, o decréscimo da atividade da $\mathrm{RN}$ também pode estar relacionado aos fatores meteorológicos menos favoráveis às plantas com metabolismo do tipo C4 (Taiz \& Zeiger, 2004). Essa afirmativa encontra suporte no fato de as menores atividades da $\mathrm{RN}$ terem sido observadas na época do ano em que as variáveis meteorológicas apresentaram valores mínimos. Também é possível que a planta não tenha absorvido a quantidade de nitrato necessária para sua adequada nutrição nessa época. Isso porque o $\mathrm{N}$ do solo chega até ás raízes principalmente por fluxo de massa que depende de grande umidade (Masclaux-Daubresse et al., 2010), e, no período em que as plantas mais precisavam de água, houve severa escassez de chuvas na região, o que pode ter influenciado negativamente a absorção de $\mathrm{N}$ e se refletido na atividade da RN. Silveira \& Crocomo (1990), ao avaliar, em condições de campo, cana-planta sob altas doses de $\mathrm{N}$ e vinhaça, verificaram que a atividade da $\mathrm{RN}$ foi maior nos estádios iniciais, com decréscimo acentuado até o início da maturação, e estes valores baixos mantiveram-se estáveis até o final do ciclo da cultura. Dessa forma, no presente trabalho, sugere-se que houve maior influência, no nível de atividade dessa enzima, de fatores meteorológicos do que da quantidade de $\mathrm{N}$ disponível no solo.

No último mês de avaliação, as plantas estavam no estádio de maturação, e, apesar dos fatores climáticos serem propícios para uma maior expressão da $\mathrm{RN}$ (Figura $1 \mathrm{~B}$ ), a atividade da enzima apresentou valor mínimo (Figura $4 \mathrm{D}$ ). Isso indica que a planta diminuiu a absorção de $\mathrm{N}$ nessa fase. 


\section{Conclusões}

1. A amostragem de 25 discos de $1 \mathrm{~cm}$ de diâmetro, coletados às $13 \mathrm{~h}$, do centro da folha do tipo +1 sem nervura, favorece a avaliação da atividade da redutase do nitrato em cana-de-açúcar (Saccharum officinarum).

2. O meio de incubação otimizado para determinação da atividade da redutase do nitrato em folhas de cana-de-açúcar deve ser composto por: $2,5 \mathrm{~mL}$ de $\mathrm{KNO}_{3}$ $300 \mathrm{mmol} \mathrm{L}-1,2,5 \mathrm{~mL}$ de tampão fosfato $285 \mathrm{mmol} \mathrm{L}^{-1}$ $\mathrm{pH} 7,3,1,0 \mathrm{~mL}$ de Tween 20 a $0,6 \%$ (v/v) e 4,0 mL de água deionizada.

3. A maior atividade da redutase do nitrato é obtida pela incubação das amostras, por $90 \mathrm{~min}$, a $32^{\circ} \mathrm{C}$, no escuro.

4. A atividade da redutase do nitrato é mais elevada nas plantas jovens formadas pela brotação da soqueira, diminui com o desenvolvimento da planta e atinge o valor mínimo na fase de maturação das plantas.

\section{Agradecimentos}

À Coordenação de Aperfeiçoamento de Pessoal de Nível Superior (Capes), pela concessão de bolsa; ao professor Samir Issa Samara, pela disponibilização da área experimental, de onde foram coletadas as amostras foliares de cana-de-açúcar; e ao professor Alan Rodrigo Panosso, pelo auxílio nas análises estatísticas.

\section{Referências}

AHMAD, S.; FAZILI, I.S.; HAQUE, R.; KHAN, S.N.; ABDIN, M.Z. Standardization and estimation of nitrate reductase activity in the leaves of Ammi majus L. (Bishops weed) in relation to sulphur deficiency and seed yield. Australian Journal of Crop Science, v.4, p.515-522, 2010.

BOBADE, S.N.; KHYADE, V.B. Influence of inorganic nutrients on the activity of enzyme, nitrate reductase in the leaves of mulberry, Morus alba (L) (M-5 variety). Research Journal of Recent Sciences, v.1, p.14-21, 2012.

CAMPBELL, W.H. Nitrate reductase structure, function and regulation: bridging the gap between biochemistry and physiology. Annual Review of Plant Physiology and Plant Molecular Biology, v.50, p.277-303, 1999. DOI: 10.1146/annurev. arplant.50.1.277.

CAZETTA, J.O.; VILLELA, L.C.V. Nitrate reductase activity in leaves and stems of tanner grass (Brachiaria radicans Napper). Scientia Agricola, v.61, p.640-648, 2004. DOI: 10.1590/ S0103-90162004000600012.
CHANDA, S.V. Factors affecting nitrate reductase activity in some monocot and dicot species. Journal of Plant Biology, v.46, p.41-45, 2003. DOI: 10.1007/BF03030300.

CRAWFORD, N.M.; KAHN, M.L.; LEUSTEK, T.; LONG, S.R. Nitrogen and sulfur. In: BUCHANAN, W.; GRUÍSSEM, R.; JONES, R. Biochemistry and molecular biology of plants. Rockville: American Society of Plant Physiologists, 2000. p.786-849.

CRUZ, F.J.R. da; LOBATO, A.K. da S.; COSTA, R.C.L. da; LOPES, M.J. dos S.; NEVES, H.K.B.; OLIVEIRA NETO, C.F. de; SILVA, M.H.L. da; SANTOS FILHO, B.G. dos; LIMA JUNIOR, J.A. de; OKUMURA, R.S. Aluminum negative impact on nitrate reductase activity, nitrogen compounds and morphological parameters in sorghum plants. Australian Journal of Crop Science, v.5, p.641-645, 2011.

DONATO, V.M.T.S.; ANDRADE, A.G. de; SOUZA, E.S. de; FRANÇA, J.G.E.; MACIEL, G.A. Atividade enzimática em variedades de cana-de-açúcar cultivadas in vitro sob diferentes níveis de nitrogênio. Pesquisa Agropecuária Brasileira, v.39, p.1087-1093, 2004. DOI: 10.1590/S0100-204X2004001100006.

EL-KOMY, H.M.; HAMDIA, M.A.; EL-BAKI, G.K.A. Nitrate reductase in wheat plants grown under water stress and inoculated with Azospirillum spp. Biologia Plantarum, v.46, p.281-287, 2003. DOI: 10.1023/A:1022819114860.

FRESCHI, L.; NIEVOLA, C.C.; RODRIGUES, M.A.R.; DOMINGUES, D.S.; VAN SLUYS, M.A.; MERCIERA, H. Thermoperiod affects the diurnal cycle of nitrate reductase expression and activity in pineapple plants by modulating the endogenous levels of cytokinins. Physiologia Plantarum, v.137, p.201-212, 2009. DOI: 10.1111/j.1399-3054.2009.01283.x.

ISHIKAWA, S.; ANDO, S.; SAKAIGAICHI, T.; TERAJIMA, Y.; MATSUOKA, M. Effects of high nitrogen application on the dry matter yield, nitrogen content and nitrate-N concentration of sugarcane. Soil Science and Plant Nutrition, v.55, p.485-495, 2009. DOI: 10.1111/j.1747-0765.2009.00381.x.

JADOSKI, C.J; TOPPA, E.V.B.; JULIANETTI, A.; HULSHOF, T.; ONO, E.O.; RODRIGUES, J.D. Fisiologia do desenvolvimento do estádio vegetativo da cana-de-açúcar (Saccharum officinarum L.). Pesquisa Aplicada e Agrotecnologia, v.3, p.169-176, 2010.

JAMUR, M.C.; OLIVER, C. Permeabilization of cell membranes. In: OLIVER, C.; JAMUR, M.C. (Ed.). Immunocytochemical methods and protocols. $3^{\text {rd }}$ ed. Totowa: Humana Press, 2010. v.588, p.63-66. DOI: 10.1007/978-1-59745-324-0_9.

JAWORSKI, E.G. Nitrate reductase assay in intact plant tissues. Biochemical and Biophysical Research Communications, v.43, p.1274-1279, 1971. DOI: 10.1016/S0006-291X(71)80010-4.

KOŁTON, A.; WOJCIECHOWSKA, R.; LEJA, M. The effect of various light conditions and different nitrogen forms on nitrogen metabolism in pepper fruits. Folia Horticulturae, v.24, p.153-160, 2012. DOI: 10.2478/v10245-012-0019-8.

KONISHI, M.; YANAGISAWA, S. The regulatory region controlling the nitrate-responsive expression of a nitrate reductase gene, NIA1, in Arabidopsis. Plant and Cell Physiology, v.52, p.824-836, 2011. DOI: 10.1093/pcp/pcr033. 
LEA, U.S.; LEYDECKER, M.T.; QUILLERÉ, I.; MEYER, C.; LILLO, C. Posttranslational regulation of nitrate reductase strongly affects the levels of free amino acids and nitrate, whereas transcriptional regulation has only minor influence. Plant Physiology, v.140, p.1085-1094, 2006. DOI: 10.1104/ pp.105.074633.

LILLO, C. Signalling cascades integrating light-enhanced nitrate metabolism. Biochemical Journal, v.415, p.11-19, 2008. DOI: 10.1042/BJ20081115.

MASCLAUX-DAUBRESSE， C.; DANIEL-VEDELE, F.; DECHORGNAT, J.; CHARDON, F.; GAUFICHON, L.; SUZUKI, A. Nitrogen uptake, assimilation and remobilization in plants: challenges for sustainable and productive agriculture. Annals of Botany, v.105, p.1141-1157, 2010. DOI: 10.1093/aob/ meq028.

MAZID, M.; KHAN, T.A.; MOHAMMAD, F. Role of nitrate reductase in nitrogen fixation under photosynthetic regulation. World Journal of Pharmaceutical Research, v.1, p.386-414, 2012.

MILLER, A.J.; CRAMER, M.D. Root nitrogen acquisition and assimilation. Plant and Soil, v.274, p.1-36, 2004. DOI: 10.1007/ s11104-004-0965-1.

MILLER, S.A. Minimizing land use and nitrogen intensity of bioenergy. Environmental Science and Technology, v.44, p.3932-3939, 2010. DOI: 10.1021/es902405a.

NELSON, D.L.; COX, M.M. Enzymes. In: NELSON, D.L.; COX, M.M. (Ed.). Lehninger: principles of biochemistry. $4^{\text {th }}$ ed. New York: Worth, 2004. p.190-237.
OLIVEIRA, L.E.M. de; MAGALHÃES, A.C.N. Atividade da redutase do nitrato in vivo em folhas de cana-de-açúcar em função das variações nas condições de ensaio. Pesquisa Agropecuária Brasileira, v.24, p.437-443, 1989.

RAIJ, B. van; CANTARELLA, H. Outras culturas industriais. In: RAIJ, B. van; CANTARELLA, H.; QUAGGIO, J.A.; FURLANI, A.M.C. Recomendações de adubação e calagem para o Estado de São Paulo. 2.ed. Campinas: IAC, 1997. p.231-244. (IAC. Boletim técnico, 100).

ROBINSON, N.; BRACKIN, R.; VINALL, K.; SOPER, F.; HOLST, J.; GAMAGE, H.; PAUNGFOO-LONHIENNE, C.; RENNENBERG, H.; LAKSHMANAN, P.; SCHMIDT, S. Nitrate paradigm does not hold up for sugarcane. PLoS One, v.6, 2011. DOI: 10.1371/journal.pone.0019045.

SHARMA, P.; DUBEY, R.S. Modulation of nitrate reductase activity in rice seedlings under aluminium toxicity and water stress: role of osmolytes as enzyme protectant. Journal of Plant Physiology, v.162, p.854-864, 2005. DOI: 10.1016/j.jplph.2004.09.011.

SILVEIRA, J.A.G. da; CROCOMO, O.J. Assimilação de nitrogênio em cana-de-açúcar cultivada em presença de elevado nível de $\mathrm{N}$ e de vinhaça no solo. Revista Brasileira de Fisiologia Vegetal, v.2, p.7-15, 1990.

SOUZA, S.R. de; STARK, E.M.L.M.; FERNANDES, M.S. Enzimas de assimilação de nitrogênio em plantas. Rio de Janeiro: Artware Projetos Culturais, 2002. 55p.

TAIZ, L.; ZEIGER, E. Fisiologia vegetal. 3.ed. Porto Alegre: Artmed, 2004. 719p.

Recebido em 27 de novembro de 2013 e aprovado em 28 de abril de 2014 